\title{
Fatigue Life Prediction of the Zirconia Fixture Based on Boundary Element Method
}

\author{
Y. W. Wang, ${ }^{1}$ J. J. Ye $\mathbb{D}^{1},{ }^{1}$ W. P. He, ${ }^{2}$ G. G. Cai, ${ }^{3}$ and B. Q. Shi ${ }^{3}$ \\ ${ }^{1}$ Research Center for Applied Mechanics, Key Laboratory of Ministry of Education for Electronic Equipment Structure Design, \\ Xidian University, Xi'an, China \\ ${ }^{2}$ School of Aerospace Science and Technology, Xidian University, Xi'an, China \\ ${ }^{3}$ Research Center for Applied Mechanics, Xidian University, Xi'an, China \\ Correspondence should be addressed to J. J. Ye; ronkey6000@sina.com
}

Received 2 April 2020; Revised 30 June 2020; Accepted 8 July 2020; Published 12 August 2020

Academic Editor: Jiawei Xiang

Copyright (c) 2020 Y. W. Wang et al. This is an open access article distributed under the Creative Commons Attribution License, which permits unrestricted use, distribution, and reproduction in any medium, provided the original work is properly cited.

\begin{abstract}
Zirconia grinding fixtures have been widely used in semiconductor industry to improve the quality and precision of the products. For maximizing the service life and minimizing the risks of accidental damage, it is critical to have a better understanding of the fatigue life of zirconia grinding fixtures. To this end, a boundary element method is developed in this paper to investigate their crack growth and fatigue life. To validate the proposed method, the stress intensity factor of a typical plate structure with initial cracks is considered. On this basis, Paris Law is employed in the boundary element model to further study the crack growth and stress distributions in the zirconia fixture under cyclic loads. Numerical results show that stress concentration occurs at the pillar of the fixture, and crack growth is perpendicular to the loading direction.
\end{abstract}

\section{Introduction}

In semiconductor industry, both grinding and polishing technologies play important roles in the procedures of product manufacturing. In order to improve the quality and precision of products, it is critical to choose an ideal auxiliary fixture to control their surface profiles $[1,2]$. Due to the properties of high strength, low density, and high wear and corrosion resistances, zirconia has been one of the most chosen materials to manufacture the fixture $[3,4]$. However, a zirconia fixture is very susceptible to microscopic cracks and damage due to its high brittleness and low fracture toughness, which will further affect the quality of grinding or polishing surfaces [5]. To insure the product quality and improve service life of zirconia fixtures, investigations of failure mechanisms and fatigue life prediction have drawn great attention in scientific community.

Finite element method (FEM) is considered to be an effective method in investigating the fracture properties [6-9]. The basic idea of a FEM approach is to discretize a continuous solution domain into many subdomains that are connected by nodes. Moreover, unknown variables in the solution domain are expressed by approximate functions. Many researchers have employed FEM to solve fracture problems [10], including fatigue crack growth [11-13] in engineering structures. Chen et al. studied the impact of incision angle and depth on the strength [14] and crack propagation [15] of zirconia ceramic. The results show that the effect of notch angles on crack propagation increased with notch depth. El-sayed et al. [16] introduced a threedimensional explicit FEM combined with the critical plane approach and multiaxial low cyclic fatigue mode to predict crack orientation and fatigue crack extension. Xue [17] employed FEM to analyze the crack growth mechanisms in the process of zirconia ceramics cutting, which was used for optimization design of process parameters. However, when a FEM is used, crack singularity is always a challenging issue and causes inefficiency in numerical simulations. This is due to the fact that an extreme refined mesh in crack regions is required to acquire a high calculation accuracy, which is extremely computationally expensive and may be impracticable. 
An alternative approach to study fracture of materials is to use boundary element method (BEM). Compared with the traditional FEM, the BEM provides a higher computational efficiency and accuracy in solving stress concentration problems. BEM has been extensively applied for the solution of stress intensity factor (SIF) $[18,19]$ and crack singularity problems [20, 21]. Ming and Yong-yuan [22] developed a time-domain boundary element method in studying dynamic SIF of a 3D crack. Excellent numerical results were acquired by employing isoparametric elements and singular elements. Peixoto et al. [23] presented a new boundary element formulation for quasi-brittle failure analysis. The boundary element method was extended to explore the quasi-brittle material fracture. Wang and Yao [24] proposed a fast BEM for the thermal analysis of fiber-reinforced composites. Numerical results clearly demonstrated the validity of the proposed model and its potential for largescale analysis. Hilgendorff et al. [25] investigated irreversible damage accumulation in high-cycle fatigue regime by using BEM. Results show that the simulation of slip bands was in good agreement with experimental observations.

In this paper, an extension of the BEM is presented to investigate fatigue crack propagations of the zirconia grinding fixture used in semiconductor industry. For each example, the open crack is considered. Stress intensity factor, which is related to the crack size and structural geometric characteristics, is accurately calculated. Moreover, a highlight of the crack evolutions under the fatigue load is studied. The outline of this paper is as follows: Section 2 introduces the advantages of BEM in studying the crack singularity problem. Section 3 presents the theory of boundary element method and the calculation procedures of the SIF. In Section 4, two typical plate structures with cracks are investigated, and numerical results are compared with finite element method and theoretical solutions to verify the proposed method. In Section 5, a 3D model of zirconia fixture is established to study its fatigue life. The conclusions are summarized in Section 6.

\section{Crack Singularity Problem}

Some classic mechanical methods can be employed to solve crack problem [26-29]. For the grinding fixtures, many transnational corporations and research institutes have invested much capital in studying their design, materials, and manufacturing technique to improve their quality. There is no doubt that the experimental-based method is only considered to be an auxiliary method to study the mechanical properties of grinding fixtures due to their variety in kind and high experimental fees.

Singularity problems, such as structural crack, can be easily found in grinding fixtures under multiple cyclic loads. The crack singularity leads to a deterioration of the performance in the procedure of finite element solution due to the singularity property of $1 / \sqrt{r}$, where $r$ is the vector in columncoordinate of crack tip [30]. To acquire the numerical solutions with a high accuracy at crack tip, researchers need to employ the denser meshes or higher-order element near the crack region. To overcome this problem, wavelets have been applied to finite element analysis to identify crack location and depth of pipe [31], as well as rotor system [32]. Meanwhile their studies mentioned above are limited to detect surface cracks. In addition, the meshes will be redivided in studying the crack growth, which leads to the reduction of calculation accuracy and efficiency in some extent.

Compared with other solution methods based on the partial differential equations, the BEM reduces the dimension of the crack problem. In addition, it is easier for the researchers to discretize the boundary rather than the solution domain. Relatively simple elements are needed to simulate the boundary shape, and the linear algebraic equations with lower order will be acquired. Therefore, the BEM is considered to be a higher effective method to solve the crack singularity problem compared to the FEM. Herein, the BEM is employed to effectively solve the SIF, and the BEM is extended to investigate the mechanical properties and predict their service life.

\section{Modeling Procedures for Crack Problems Based on the BEM}

3.1. Scheme of the BEM. The boundary integral equation in a $3 \mathrm{D}$ elastic domain without consideration of body forces can be written as follows [33]:

$$
\begin{aligned}
& C_{i j}(P) U_{j}(P)+\int_{S} U_{j}(Q) T_{i j}^{*}(P, Q) \mathrm{d} S(Q) \\
& =\int_{S} T_{j}(Q) U_{i j}^{*}(P, Q) \mathrm{d} S(Q)
\end{aligned}
$$

where $U_{j}$ and $T_{j}$ represent the displacement and traction components, respectively. $U_{i j}^{*}$ and $T_{i j}^{*}$ are their corresponding fundamental solutions. $P$ and $Q$ are any two points in the solution domain. $S$ and $C_{i j}$ are the boundary surface and geometrical coefficients, respectively. It should be noted that the coefficients $C_{i j}$ are closely dependent on the location of the point $P$. When $P$ is located in the solution domain, $C_{i j}=\delta_{i j}$. When $P$ is on a smooth boundary, $C_{i j}=1 / 2$, and when $P$ is outside the solution domain, $C_{i j}=0$.

In each element, the local coordinate $X_{i}$ can be represented by the node global coordinate $X_{i}^{l}$ in the element by employing the interpolation function $N_{l}(\xi, \eta)$, that is,

$$
X_{i}=\sum_{l=1}^{M} N_{l}(\xi, \eta) X_{i}^{l},
$$

where $M$ indicates the number of nodes in each element. $\xi$ and $\eta$ are the local coordinates as shown in Figure 1. $X_{i}^{l}$ indicates the global coordinates of the node $l$ relative to the element $i$.

In each element, the traction forces $T_{j}$ and displacements $U_{j}$ in local coordinate system can be expressed as

$$
\left\{\begin{array}{l}
U_{j}=\sum_{l=1}^{M} N_{l}(\xi, \eta) U_{j}^{(l)}, \\
T_{j}=\sum_{l=1}^{M} N_{l}(\xi, \eta) T_{j}^{(l)},
\end{array}\right.
$$




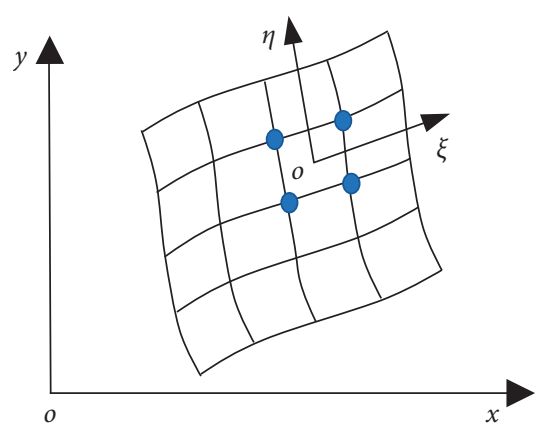

FIGURE 1: The relationship between global coordinate system and local coordinate system.

where $U_{j}^{(l)}$ and $T_{j}^{(l)}$ indicate the displacement and traction components along the coordinate axis $j$ in global coordinate system.

After discretizing into surface elements, the boundary integral equation can be expressed as follows:

$$
\begin{aligned}
C_{i j}(P) U_{j}(P)= & \sum_{e=1}^{N_{e}}\left\{\sum_{l=1}^{M}\left[\int_{-1}^{1} \int_{-1}^{1} N_{K}(\xi, \eta) U_{i j}^{*}(P, Q)|J| \mathrm{d} \xi \mathrm{d} \eta\right] T_{j}^{(l)}\right\} \\
& -\sum_{e=1}^{N_{e}}\left\{\sum_{l=1}^{M}\left[\int_{-1}^{1} \int_{-1}^{1} N_{K}(\xi, \eta) T_{i j}^{*}(P, Q)|J| \mathrm{d} \xi \mathrm{d} \eta\right] U_{j}^{(l)}\right\},
\end{aligned}
$$

where $J$ is Jacobian matrix. The boundary $S$ is discretized into $N_{e}$ elements with $N_{b}$ boundary nodes. According to the Gauss numerical integration formula, it can be written as

$$
\left\{\begin{array}{l}
\int_{-1}^{1} \int_{-1}^{1} N_{K}(\xi, \eta) U_{i j}^{*}(P, Q)|J| \mathrm{d} \xi \mathrm{d} \eta=\widehat{G}_{i j}^{e l}(P), \\
\int_{-1}^{1} \int_{-1}^{1} N_{K}(\xi, \eta) T_{i j}^{*}(P, Q)|J| \mathrm{d} \xi \mathrm{d} \eta=\widehat{H}_{i j}^{e l}(P) .
\end{array}\right.
$$

Substituting equation (5) into equation (4), it can be written as

$$
C_{i j}(P) U_{j}(P)=\sum_{e=1}^{N_{e}} \sum_{l=1}^{M} \widehat{G}_{i j}^{e l}(P) T_{j}^{(l)}-\sum_{e=1}^{N_{e}} \sum_{l=1}^{M} \widehat{H}_{i j}^{e l}(P) U_{j}^{(l)} .
$$

By employing the transformation matrix $Z_{j}^{e l}$, node values of $U_{j}^{(l)}$ and $T_{j}^{(l)}$ in global coordinate system are written as follows:

$$
\begin{gathered}
U_{j}^{(l)}=Z_{j}^{e l} \mathbf{U}, \\
T_{j}^{(l)}=Z_{j}^{e l} \mathbf{T},
\end{gathered}
$$

where $\mathbf{U}$ and $\mathbf{T}$ are displacement and traction column vectors of the boundary nodes. The transformation matrix $Z_{j}^{e l}$ is the diagonal matrix. Substituting equation (7) into equation (6), the equations can be easily expressed in matrix format, that is,

$$
\mathbf{C U}=\mathbf{G T}-\mathbf{H}^{\prime} \mathbf{U}
$$

where

$$
\left\{\begin{array}{l}
G_{i j}(P)=\sum_{e=1}^{N_{e}} \sum_{l=1}^{M} \widehat{G}_{i j}^{e l}(P) Z_{j}^{e l}, \\
H_{i j}^{\prime}(P)=\sum_{e=1}^{N_{e}} \sum_{l=1}^{M} \widehat{H}_{i j}^{e l}(P) Z_{j}^{e l} .
\end{array}\right.
$$

3.2. Stress Intensity Factor. In fracture mechanics, the open mode or type I crack (as shown in Figure 2) is one of the most common cracks. Herein, the SIF of the crack is studied by BEM to lay a foundation for predicting the crack evolutions under cycling loadings.

The SIF, which relates to many factors, such as crack size and structural geometric characteristics, reflects the strength of elastic stress field at crack tip. In the modeling procedures by the BEM, longitudinal stresses $\left(\sigma_{x}\right.$ and $\left.\sigma_{y}\right)$ and shear stress $\tau_{x y}$ at the crack tip in global coordinate system as shown in Figure 3 can be expressed as follows: where the coordinate system $r-\theta$ indicates the polar coordinate of point $A$ near the crack tip as shown in Figure 3(b).

$$
\left\{\begin{array}{l}
\sigma_{x}=\frac{K I}{\sqrt{2 \pi r}} \cos \frac{\theta}{2}\left(2-\sin \frac{\theta}{2} \sin \frac{3 \theta}{2}\right), \\
\sigma_{y}=\frac{K I}{\sqrt{2 \pi r}} \cos \frac{\theta}{2}\left(1-\sin \frac{\theta}{2} \sin \frac{3 \theta}{2}\right), \\
\tau_{x y}=\frac{K I}{\sqrt{2 \pi r}} \sin \frac{\theta}{2} \cos \frac{\theta}{2} \cos \frac{3 \theta}{2},
\end{array}\right.
$$
as

$$
\left\{\begin{array}{l}
u \\
v
\end{array}\right\}=2(1+v) \frac{K I}{E} \sqrt{\frac{r}{2 \pi}}\left\{\begin{array}{c}
\cos \frac{\theta}{2}\left[1-2 v+\sin ^{2} \frac{\theta}{2}\right] \\
\sin \frac{\theta}{2}\left[2-2 v+\cos ^{2} \frac{\theta}{2}\right]
\end{array}\right\},
$$

where the parameters $u$ and $v$ denote the displacement in horizontal and vertical directions, respectively. $E$ is the elastic modulus; $v$ is Poisson's ratio.

If the angle $\theta$ is equal to $180^{\circ}$, the displacement components at crack region can be simplified as

$$
v=\frac{4(1+v)(1-v)}{E} \sqrt{\frac{r}{2 \pi}} K I
$$

By employing the displacement components derived from the BEM, the SIF can be expressed as

$$
K I=\frac{E}{(1+v)(1-v)} \sqrt{\frac{2 \pi}{r}} v_{\mathrm{BEM}} .
$$




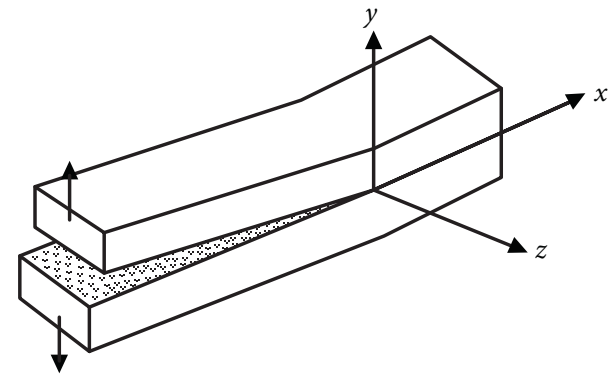

Figure 2: Open crack mode.

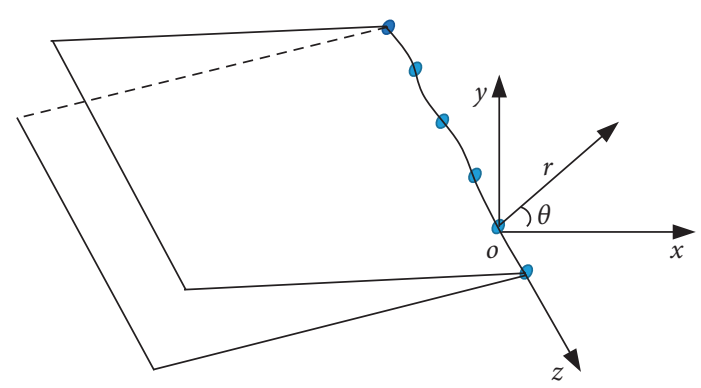

(a)

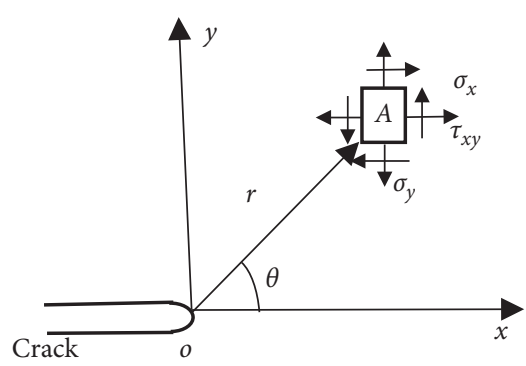

(b)

FIgURE 3: Stress status near the crack tip. (a) Diagram of a threedimensional crack. (b) Crack coordinate systems.

\section{Crack Propagation Analysis of the Typical Structures}

To validate the proposed BEM method, KI of the plate structures made by zirconia materials are compared with the FEM and theoretical results. On this basis, the crack propagation is further discussed according to the maximum circumferential stress criterion [34]. The zirconia material parameters are as follows: elastic modulus is $220 \mathrm{GPa}$, and Poisson's ratio is 0.25 .

4.1. Rectangular Plate with Bilateral Cracks. A circular hole of $\Phi 2 \mathrm{~mm}$ located at the geometric center of the plate, whose dimensions are $50 \mathrm{~mm}$ length, $10 \mathrm{~mm}$ width, and $1 \mathrm{~mm}$ thickness, is considered as shown in Figure 4. In order to easily and clearly observe crack evolutions, the bilateral precracks with length of $0.1 \mathrm{~mm}$ are implanted at the maximum stress regions. The constraints and external loadings are shown in Figure 4.
For the open crack mode as shown in Figure 2, the theoretical solutions of $K I_{t}$ can be written as [31]

$$
K I_{t}=F \sigma \sqrt{\pi a},
$$

where the parameters $\sigma$ and $a$ indicate the stress at crack tip and the distance between crack tip and the center of circular hole, respectively. $F$ indicates an effective coefficient and its value 0.84 is employed according to [35]. It can be easily found that the SIF is closely dependent on crack length. The value of $K I_{t}$ is equal to $15.6153 \mathrm{MPa} \cdot \mathrm{m}^{1 / 2}$ when the initial crack length is equal to $0.1 \mathrm{~mm}$.

To discuss the relations between SIF and crack length, the boundary element model of the plate as shown in Figure 4 is established. When the multiregion algorithm is used, the model is divided into two regions by the crack surface along crack direction. In the modeling procedures, the quadrilateral elements are employed to discrete the plate structure. In the stress concentration region near the hole, more density triangle elements are required to solve the stresses with a high accuracy. For a comparison, numerical results acquired by the FEM are also investigated under an identical condition. Numerical results $K I$ of the plate with four different crack lengths $(0.1 \mathrm{~mm}, 0.2 \mathrm{~mm}$, $0.3 \mathrm{~mm}$, and $0.4 \mathrm{~mm}$ ) are shown in Figure 5(a). Here, the horizontal axis and vertical axis in this figure indicate the number of discrete points and theoretical results of the $K I$ acquired by the BEM, respectively. It can be easily found that the crack growth will sharply increase the SIF at crack tip. Meanwhile it is interesting to mention that $K I$ is slightly dependent on quantities of discrete points. In other words, it takes relatively less discrete points to solve the SIF with a high accuracy by using the BEM. To further validate the method, numerical results by the FEM and theoretical solutions by experience equations are both considered. The error analysis can be seen in Figure 5(b). It can be concluded that the BEM agrees well with the FEM when the crack growth is from $0.2 \mathrm{~mm}$ to $0.4 \mathrm{~mm}$. If a small crack of $0.1 \mathrm{~mm}$ is considered, the BEM provides a higher accuracy than the FEM, and the relative error is equal to $8.22 \%$. A higher calculation accuracy of the SIF will be acquired by the BEM when the crack growth from $0.3 \mathrm{~mm}$ to $0.4 \mathrm{~mm}$ is considered in the case.

Figure 6 indicates stress distributions and crack evolutions of the plate by employing the BEM. It can be easily found that the maximum stress is located at the crack tip, and crack growth is perpendicular to the loading direction. In addition, the stress distribution variations with respect to crack evolutions can be easily discerned. The maximum stresses at the crack tip are sharply increased with the crack evolution. In detail, the maximum stress is approximated to $35.05 \mathrm{MPa}$ once the crack length of $0.5 \mathrm{~mm}$ is considered as shown in Figure 6(a). Once when the crack extends to $4.0 \mathrm{~mm}$ as shown in Figure $6(\mathrm{~h})$, the maximum stress at crack region increases rapidly to $541.0 \mathrm{MPa}$. In addition, the identical crack propagations will be found in both sides of the circle hole due to the structural symmetry of the studied plate. 


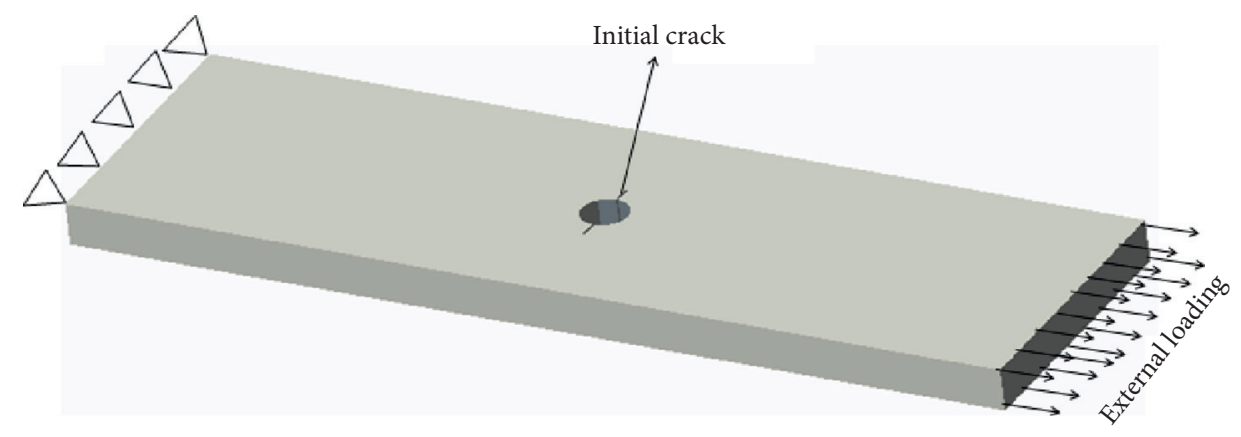

FIgURE 4: Plate structure with bilateral cracks.

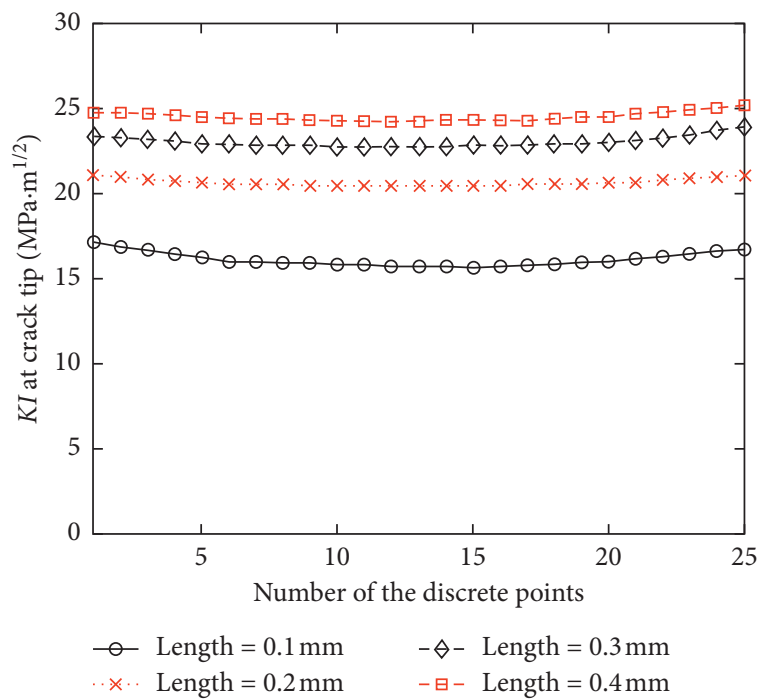

(a)

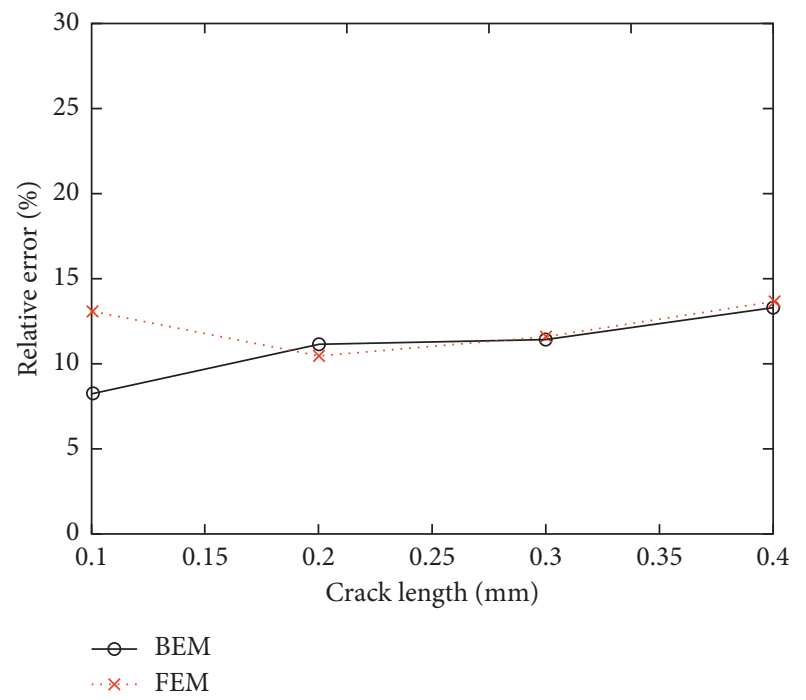

(b)

FIgURE 5: (a) KI value along the crack front. (b) Relative error comparisons between the FEM and the BEM.

4.2. Rectangular Plate with a Unilateral Crack. A rectangular plate made of zirconia materials with a unilateral crack is also considered here to further validate the established model. The dimension parameters are as follows: length, $10 \mathrm{~mm}$; width, $3 \mathrm{~mm}$; and height, $30 \mathrm{~mm}$. A rectangular precrack with a length of $1 \mathrm{~mm}$ is located at the stress concentration region to investigate the crack growth. The constraints and external loadings are applied on the structure as shown in Figure 7.

For the fracture mode of this plate with a unilateral crack as shown in Figure 7, theoretical solutions of the SIF $K I_{(\alpha)}$ can be acquired according to the manual of the SIF [31]; that is,

$$
K I_{(\alpha)}=F \sigma \sqrt{\pi a},
$$

where the parameters $F$ and $a$ indicate the related coefficient and crack length, respectively. When the initial crack length $a=1 \mathrm{~mm}$ is considered, the parameter $F$ is equal to 1.2 . Taking these parameters into equation (15), the theoretical result of $K I_{(\alpha)}$ is $20.3042 \mathrm{MPa} \cdot \mathrm{mm}^{1 / 2}$.
For investigating the $K I$ variations with respect to crack growth, the BEM model is established. Quadrilateral elements are used to discretize the structure. With a full consideration of stress concentration in the crack region and improving the calculation efficiency, one-quarter discretization ratio of the elements away from the crack region is employed in establishing the model. Figure 8(a) presents the numerical results of $K I$ at crack tip, and five different lengths $(1 \mathrm{~mm}, 2 \mathrm{~mm}, 3 \mathrm{~mm}, 4 \mathrm{~mm}$, and $5 \mathrm{~mm})$ are considered in the example. Similar to the results of a plate with bilateral cracks, it can be easily found that the unilateral crack growth will also sharply increase KI. In addition, it is difficult for researchers to discern the effect of the number of discrete points on calculation accuracy when $K I$ is considered. To further validate the established model, results by the FEM and theoretical method are also considered, and relative errors are shown in Figure 8(b). In general, numerical results by the BEM agree well with the theoretical results. In addition, it can be concluded that the BEM provides a higher accuracy than the FEM. In detail, the 


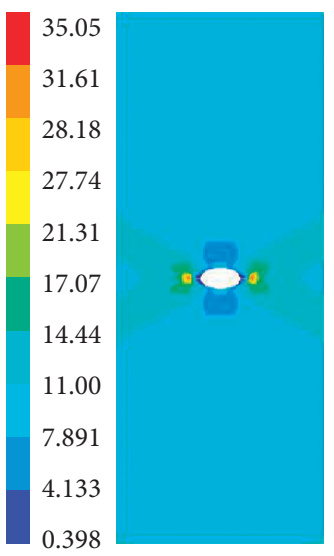

(a)

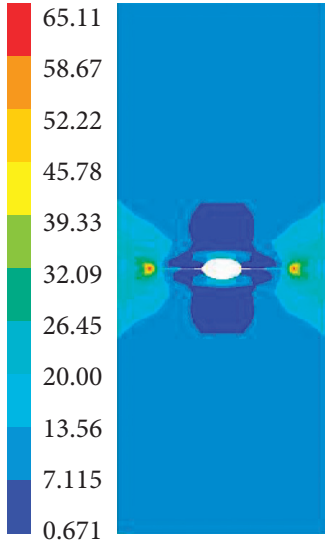

(e)
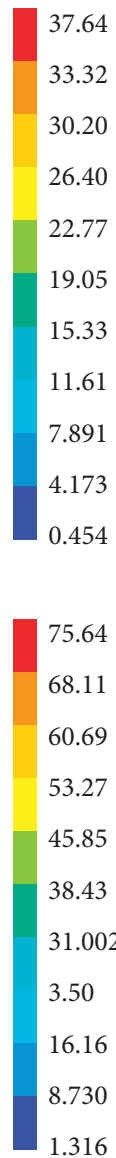

1.316

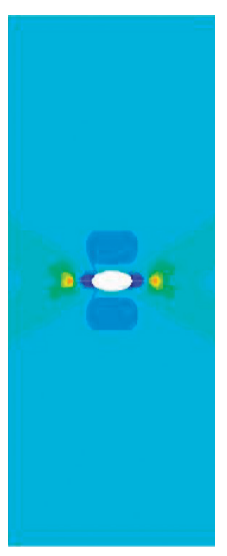

(b)

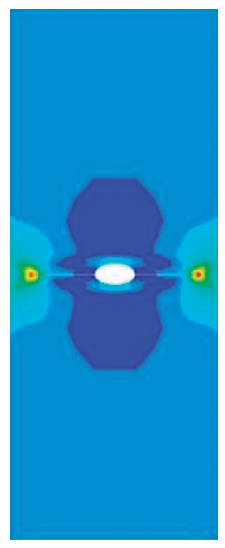

(f)

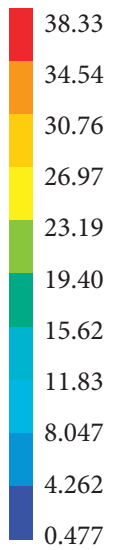

(c)
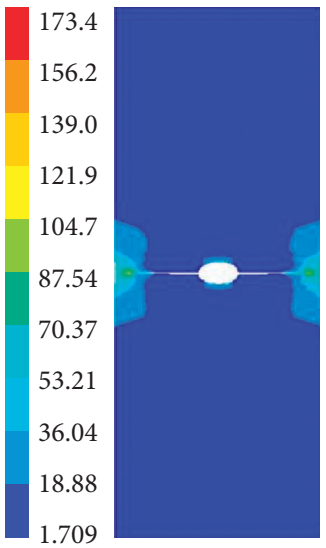

(g)

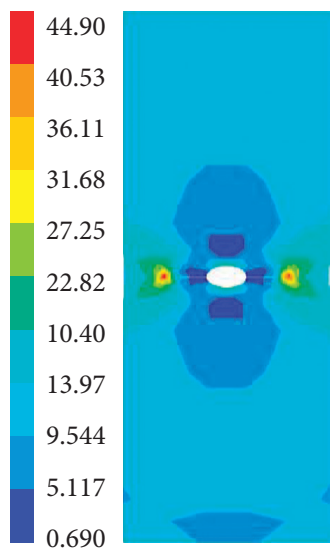

(d)

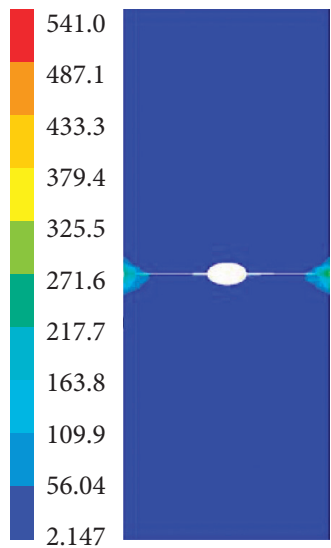

(h)

Figure 6: Mises stress distributions of the plate with different crack lengths: (a) $0.5 \mathrm{~mm}$, (b) $1.0 \mathrm{~mm}$, (c) $1.5 \mathrm{~mm}$, (d) $2.0 \mathrm{~mm}$, (e) $2.5 \mathrm{~mm}$, (f) $3.0 \mathrm{~mm}$, (g) $3.5 \mathrm{~mm}$, and (h) $4.0 \mathrm{~mm}$.

errors acquired by the BEM and FEM are $1.75 \%$ and $7.65 \%$ when crack length of $1 \mathrm{~mm}$ is considered. The maximum relative error acquired by the BEM is $0.64 \%$ when crack extends to $3 \mathrm{~mm}$.

In order to execute the crack propagation analysis, a precrack with length of $1 \mathrm{~mm}$ is also implanted into the boundary element model as shown in Figure 9(a). Figures 9(b)-9(i) indicate crack evolutions of the plate with the increasing of external loading. It can be seen that the maximum stress is located at the crack tip, and the crack growth is perpendicular to the loading direction. With the crack growth, the maximum stress will be further increased. In detail, the maximum stress is $18.01 \mathrm{MPa}$ when an initial crack of $1 \mathrm{~mm}$ is considered. With an increase of crack length, the maximum stress of the plate at crack tip is 256.1 MPa when the crack length of $7 \mathrm{~mm}$ is considered in the example.

\section{Fatigue Crack Propagation Analysis of the Zirconia Grinding Fixture}

Figure 10 is a typical 3D model of grinding fixtures made by zirconia materials, which is widely used in semiconductor processing. For this fixture, since it is used to replace the old fixture of steel material, it had been special toughening treatment to improve property. The components $\mathrm{C}$ and C' indicate the fixed pin holes, which are used to restrain the grinding fixture. The symbols A1-G1 indicate the force adjusting heads of the fixture. In the manufacturing process, the strip-shaped workpiece is constrained on the surface of grinding fixture. The structural dimensions of the fixture are as follows: length of $220 \mathrm{~mm}$, width of $50 \mathrm{~mm}$, and thickness of $5 \mathrm{~mm}$.

Due to the high hardness and brittleness of zirconia materials, machined surfaces of the fixture are prone to produce microcracks, and the cracks will immediately accumulate. In service, periodical cycling loads will be applied on the holes of the adjusting heads to obtain a desired bottom surface profile. It is critical for researchers to grasp crack status and fatigue life to maximize their service life. To this end, the $3 \mathrm{D}$ model of the fixture based on the BEM is established. In the fatigue life analysis, the surfaces of the fixed pin holes $\mathrm{C}$ and $\mathrm{C}^{\prime}$ are fully restrained. A cyclic loading is supposed to apply on the hole of force adjusting heads A1-G1. An external load of $0.1 \mathrm{~N}$ is applied on the surface $K$ to grasp stress distributions of the fixture.

The flow chart of fatigue crack predictions is shown in Figure 11; it can be summarized as follows: 


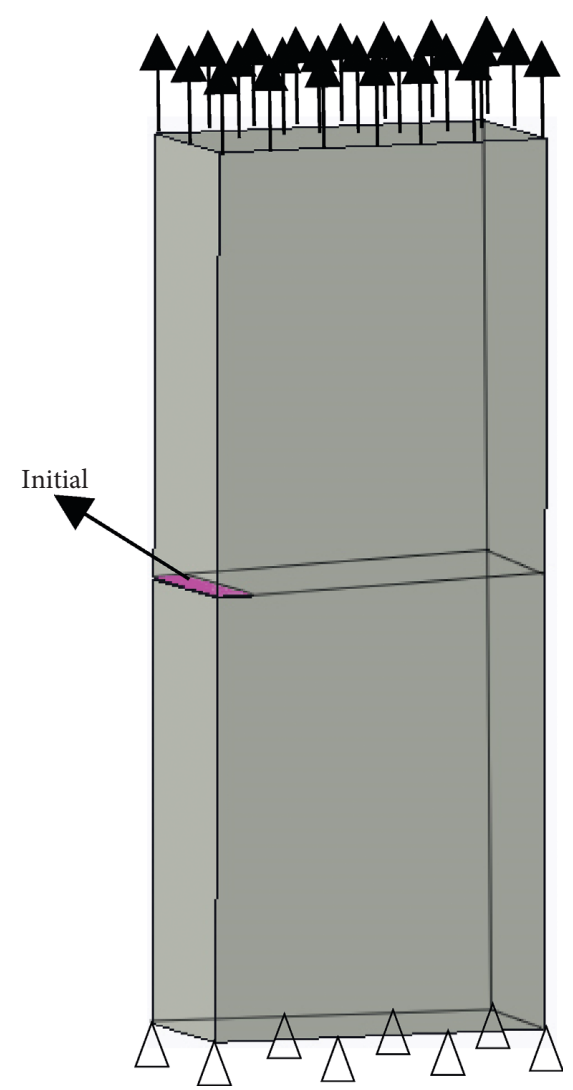

FIgURE 7: Plate structure with a unilateral crack.

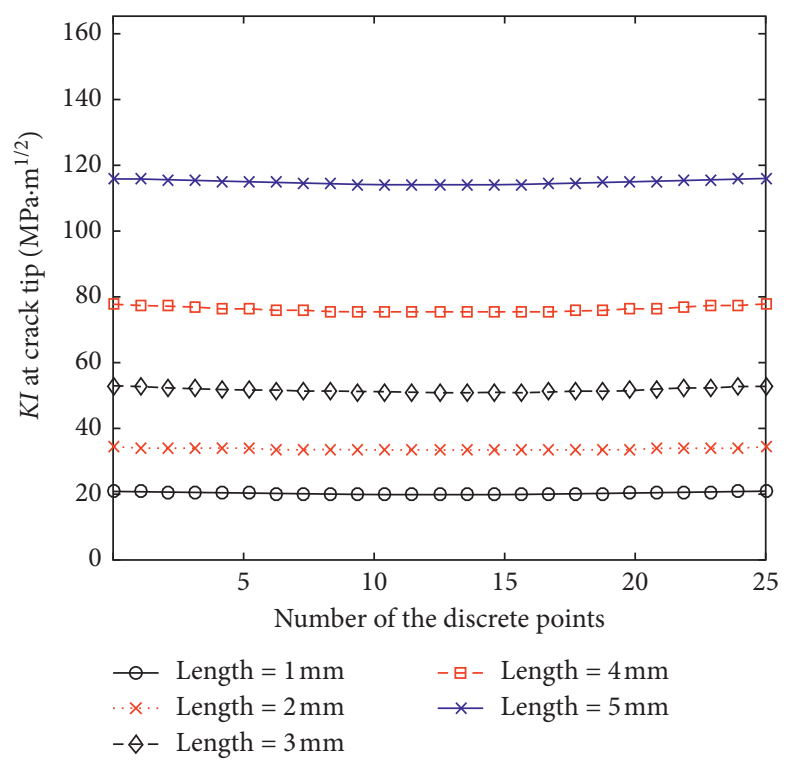

(a)

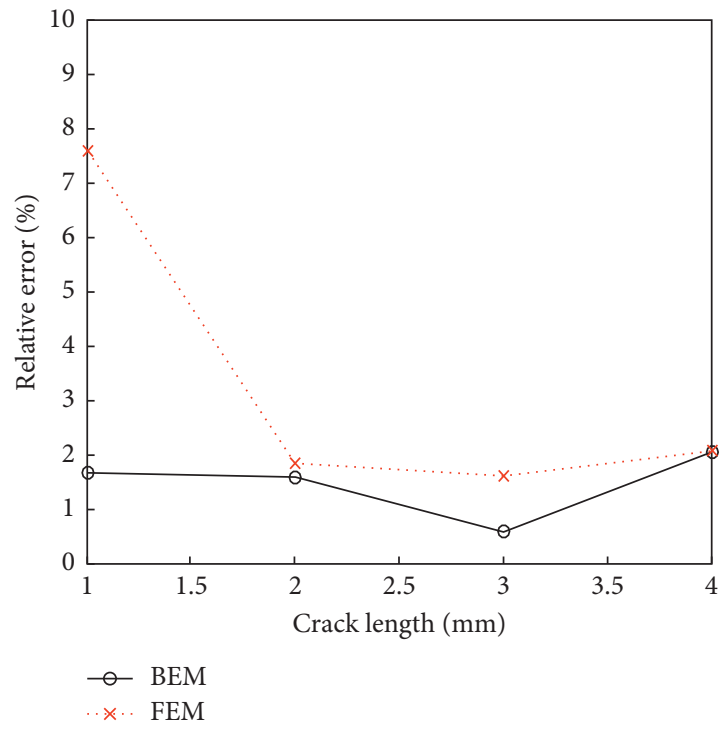

(b)

FIGURE 8: KI values at the crack tip. (a) Relations between discrete points and KI. (b) Relative error comparisons between the FEM and the BEM.

(1) The Object Solid Modeler (OSM) is employed to establish the 3D BEM of the grinding fixture.

(2) Meshing the surface and inputting the material properties, boundary conditions. The discretized model based on the BEM is established by employing the Fracture Analysis Code (FRANC3D).

(3) Before the fatigue analysis, a small external load is applied on the fixture, and the stress and 


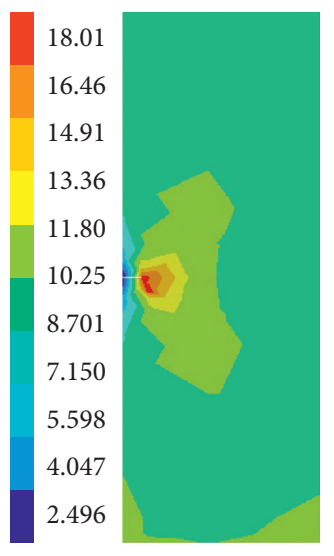

(a)

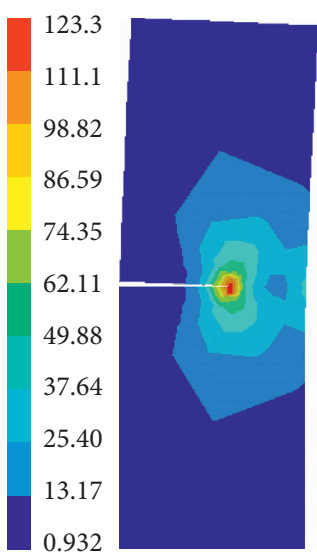

(f)

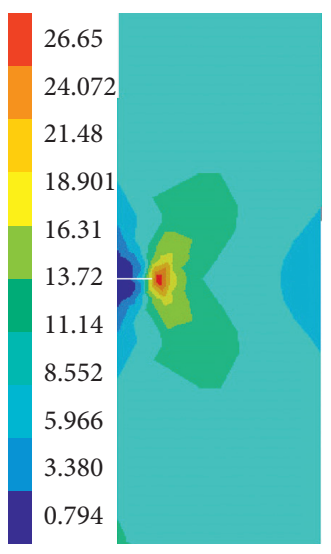

(b)

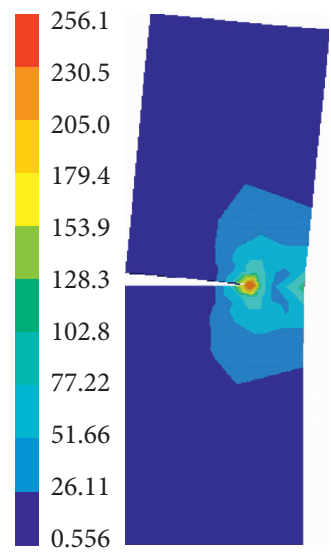

(g)

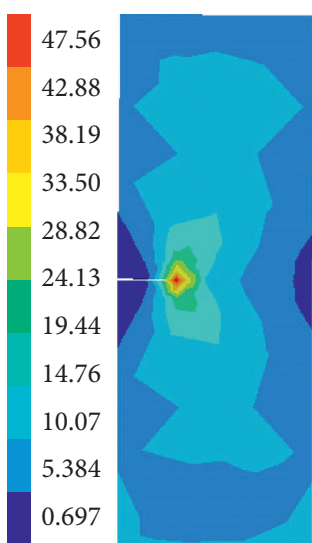

(c)

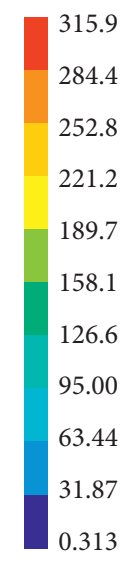

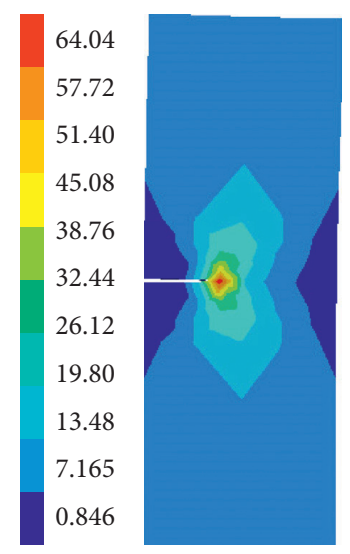

(d)

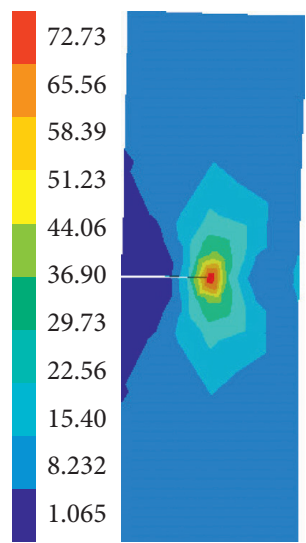

(e)

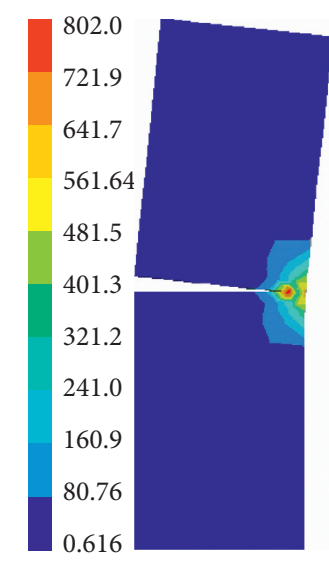

(i)

Figure 9: Mises stress distributions of plate with different crack lengths: (a) $1 \mathrm{~mm}$, (b) $2 \mathrm{~mm}$, (c) $3 \mathrm{~mm}$, (d) $4 \mathrm{~mm}$, (e) $5 \mathrm{~mm}$, (f) $6 \mathrm{~mm}$, (g) $7 \mathrm{~mm}$, (h) $8 \mathrm{~mm}$, and (i) $9 \mathrm{~mm}$.

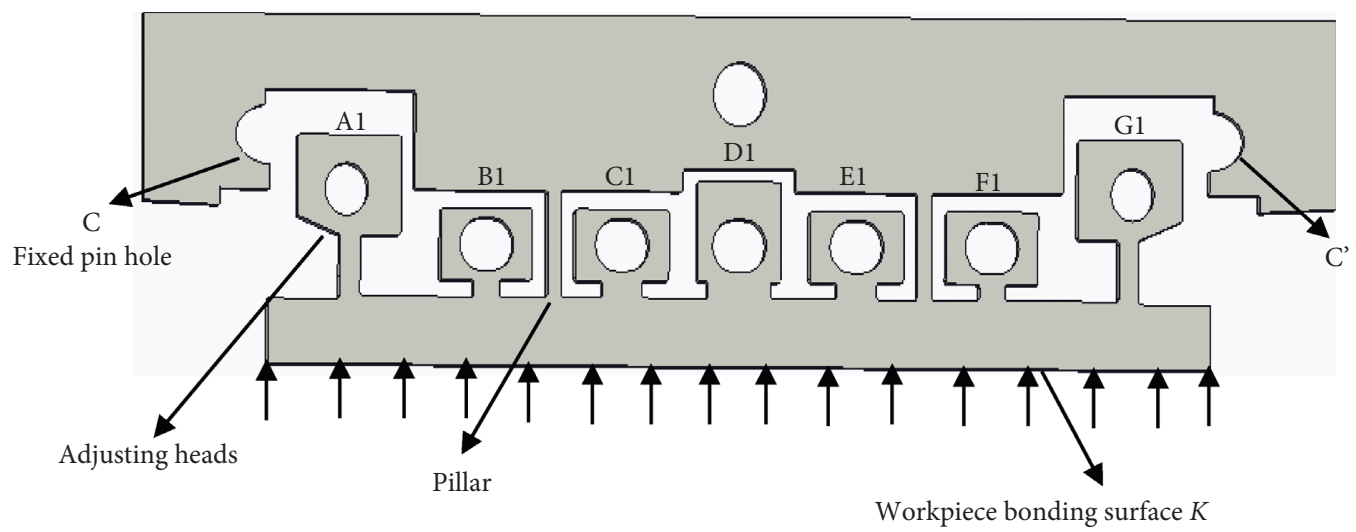

Figure 10: The model of grinding fixture.

deformation cloud diagrams will be acquired. According to the stress distributions, an initial crack is embedded into the maximum stress area of the fixture.

(4) Applying cyclic loading on the fixture, the crack will accumulate and extend. At each crack increment, the SIF will be recalculated.
(5) According to the history data of the SIF and the corresponding crack length, the fatigue life of fixture will be determined.

The process of crack propagation can be summarized as follows:

(1) Based on the boundary element method (BEM), the displacement field of crack surface is solved, and the 


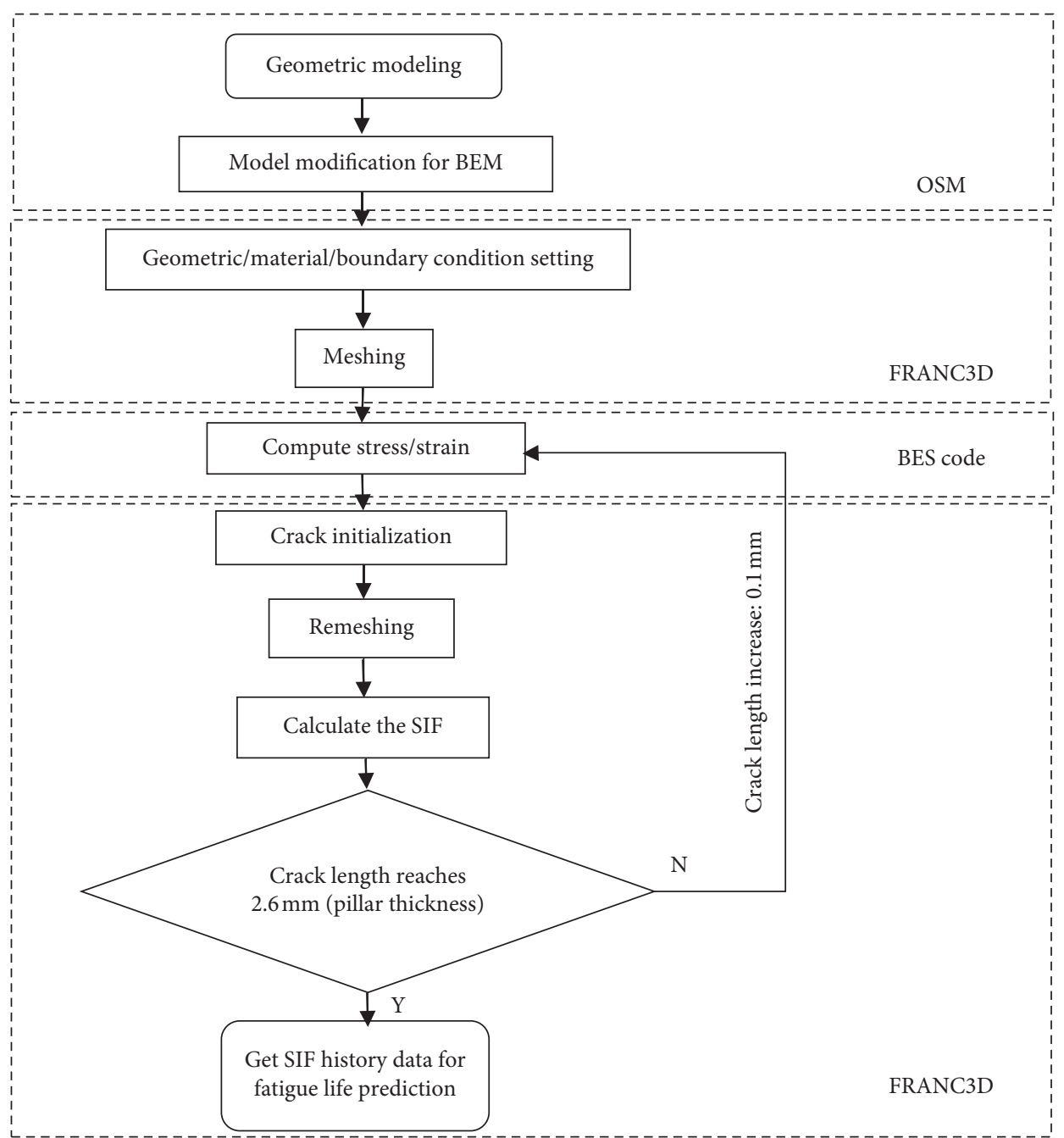

Figure 11: The flow diagram of FRANC3D.

distribution of SIF along the current crack front is solved by crack opening displacement (COD) fitting method

(2) Based on classical Paris Erdogan Law, the propagation size and position of each point on the crack front edge are calculated

(3) The new crack front is obtained by fitting the new position after propagation by least square method

(4) Repeat the above steps for the specified simulation accuracy

5.1. Stress Distributions and Crack Propagations. In the mechanical analysis of the fixture, it will be found that the maximum stress is located at the root of the pillar $P$ as shown in Figure 12.

When calculating the stress intensity factors of threedimensional cracks by FRANC3D, the cracks are usually simplified to round, ellipse, and rectangle according to the actual situation. According to the experimental observation, the fatigue crack in the pillar of the fixture is basically rectangular, which is continuously expanding forward. Herein, we simplify the crack model into a rectangle in order to further investigate the fatigue crack propagation, and a unilateral crack of $0.1 \mathrm{~mm}$ is implanted into the fixture as shown in Figure 13(a). Figures 13(b)-13(f) indicate the relations between crack lengths $(0.5 \mathrm{~mm}, 1.0 \mathrm{~mm}, 1.5 \mathrm{~mm}$, $2.0 \mathrm{~mm}$, and $2.5 \mathrm{~mm}$ ) and stress distributions. Similar to the conclusions acquired by the plate structure, the maximum stress in each case is located at the crack tip, and the crack growth is perpendicular to the loading direction. In detail, when the crack length is $0.1 \mathrm{~mm}$ as shown in Figure 13(a), the maximum stress and $K I$ at crack tip are $162.0 \mathrm{MPa}$ and $61.26 \mathrm{MPa} \cdot \mathrm{mm}^{1 / 2}$, respectively. With the crack growth, the maximum stress at crack region will be sharply increased as shown in Figures 13(b)-13(f). For instance, the maximum stress and $K I$ are $776.2 \mathrm{MPa}$ and $\mathrm{KI}=394.4 \mathrm{MPa} \cdot \mathrm{mm}^{1 / 2}$ when the crack extends to $1.5 \mathrm{~mm}$, respectively.

5.2. Fatigue Crack Propagation Analysis. In order to determine the fatigue life of the fixture under cyclic loads, herein the classical Paris Erdogan Law is employed. The 


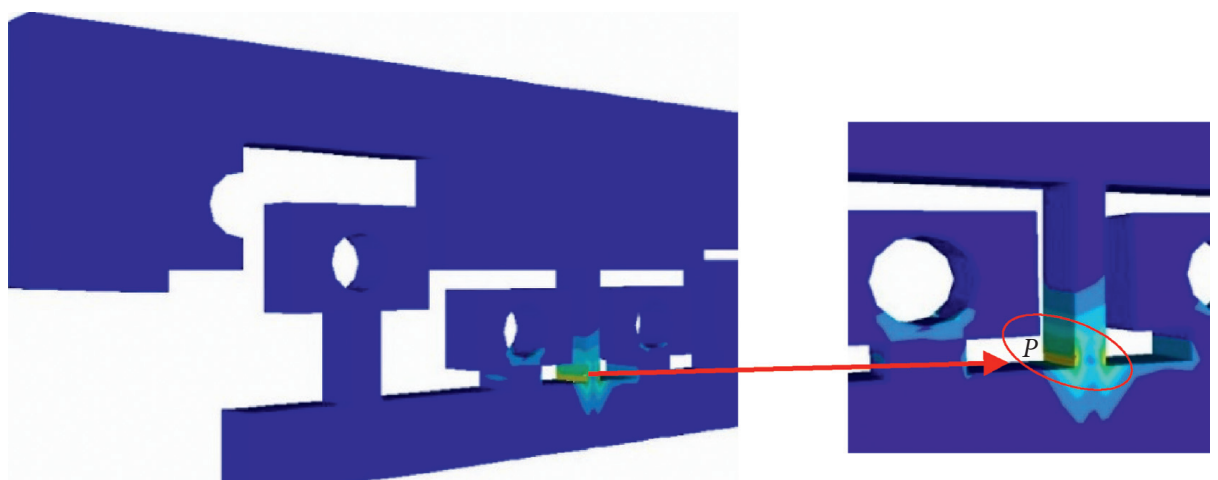

(a)

(b)

Figure 12: Mises stress distributions of the fixture. (a) Fixture. (b) Partial enlarged figure.

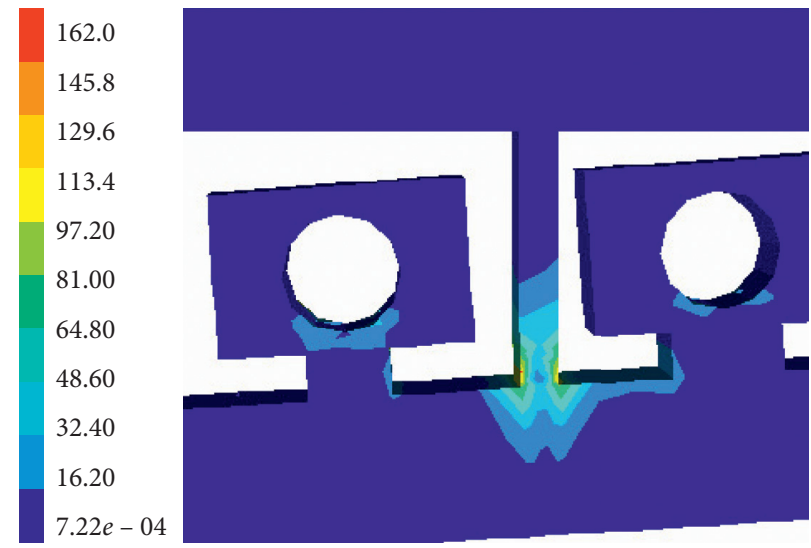

(a)

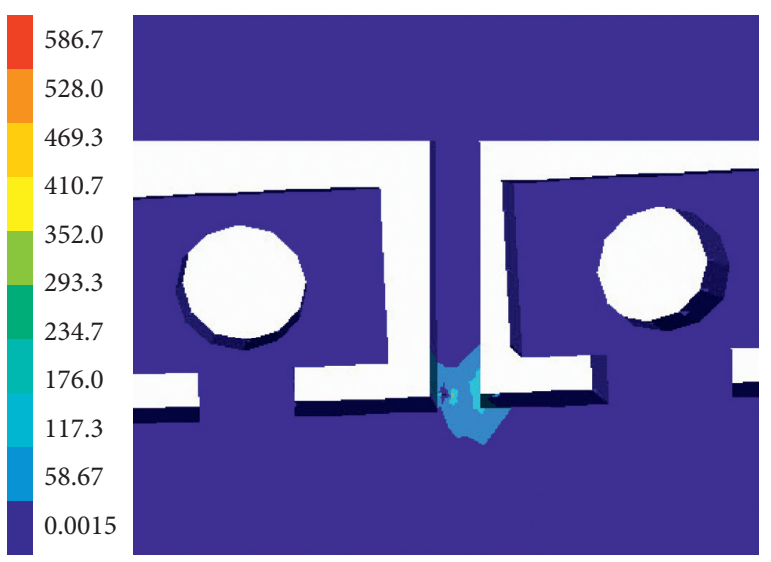

(c)

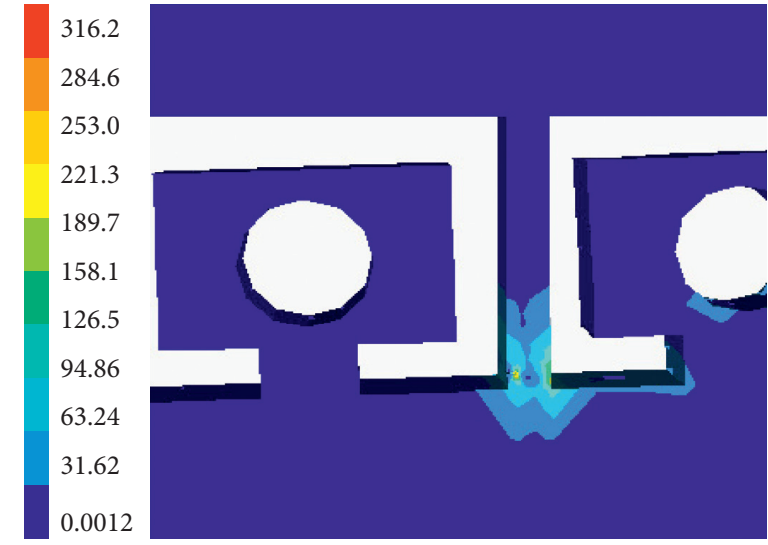

(b)

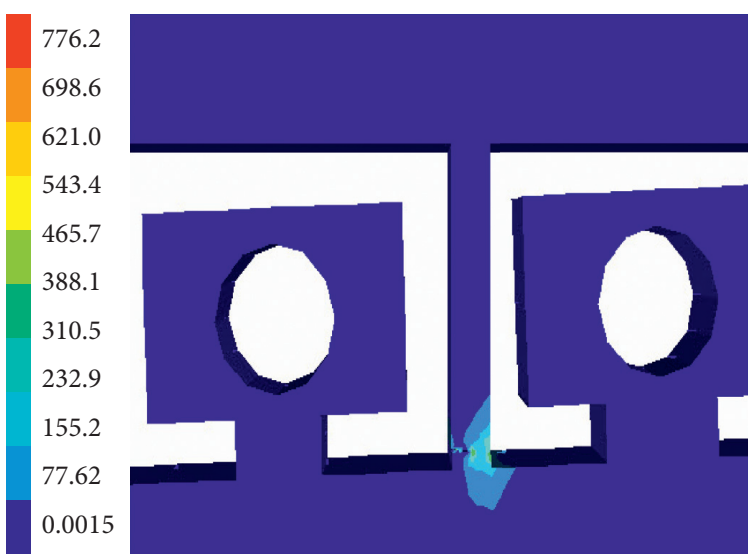

(d)

FIgURE 13: Continued. 


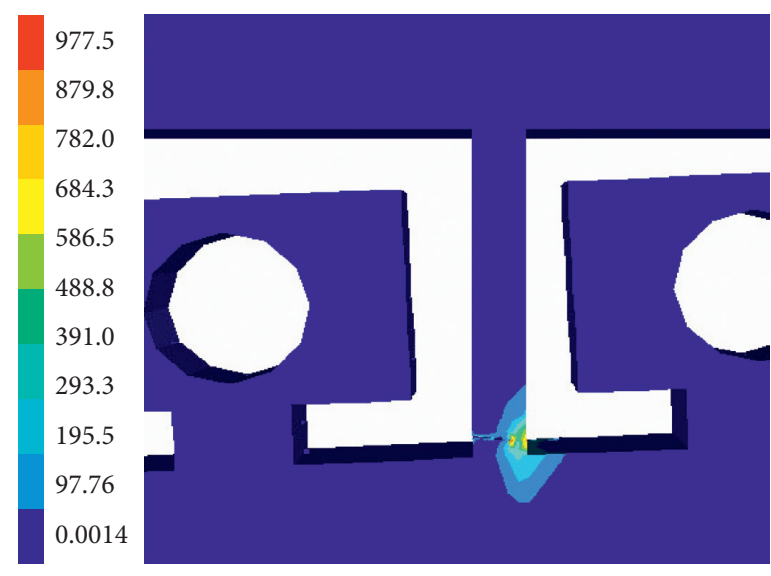

(e)

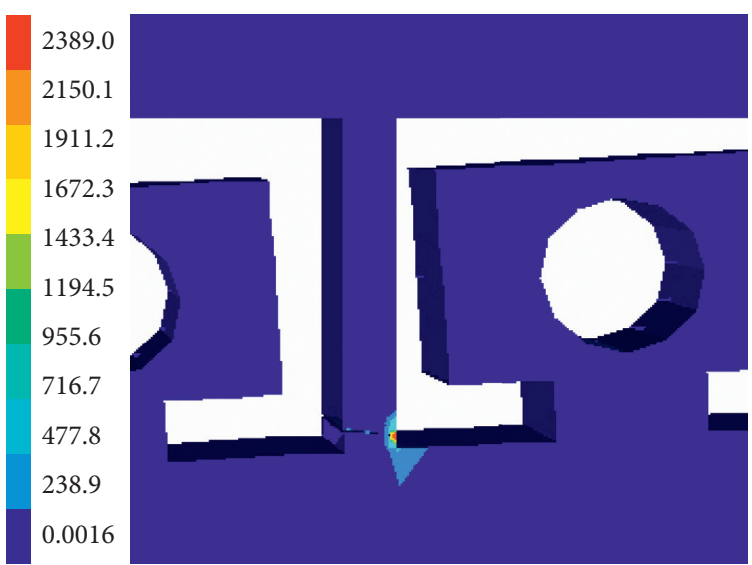

(f)

Figure 13: Mises stress distributions of the fixture with a unilateral crack. (a) $0.1 \mathrm{~mm}$. (b) $0.5 \mathrm{~mm}$. (c) $1.0 \mathrm{~mm}$. (d) $1.5 \mathrm{~mm}$. (e) $2.0 \mathrm{~mm}$. (f) $2.5 \mathrm{~mm}$.

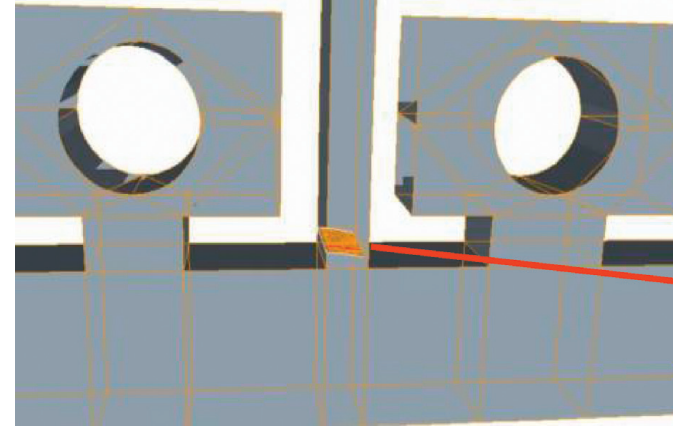

(a)

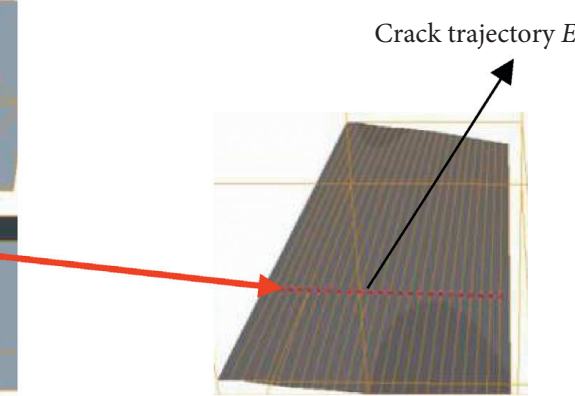

(b)

Figure 14: Crack in the fixture. (a) Cross section of the crack. (b) Partial enlarged figure of the crack trajectory.

relationship between crack growth rate and SIF range can be written as $[36,37]$

$$
\frac{\mathrm{d} a}{\mathrm{~d} N}=C\left(\Delta K_{\mathrm{eff}}\right)^{m}
$$

where $N$ and $a$ indicate the number of applied loadings and crack length, respectively. $\mathrm{d} a / \mathrm{d} N$ describes the crack growth per cycle; it has a power law relationship with the stress intensity factor amplitude. $\Delta K_{\text {eff }}$ is a parameter related to the SIF. $C$ and $m$ are material constants. Take $C=2.5 \times 10^{-14}$ and $m=4.5$.

According to the crack propagation law studies mentioned above, an initial crack is supposed and located at the bottom of the pillar. The crack evolution trajectory in the fixture can be confirmed as shown in Figure 14. The SIF at the crack tip along the crack trajectory $E$ (Figure 14(b)) can be first calculated. When dealing with the three-dimensional crack propagation problem, the maximum circumferential stress criterion is used to judge the propagation direction of the crack front edge under the specified length.

Stress intensity factor (SIF) obtained from each crack growth step (crack length) can be determined by maximum circumferential stress. As shown in Figure 15, it can be easily seen that the relations between $K I$ at crack tip and crack length show an evidently nonlinear property. When the cracks extend to $1.2 \mathrm{~mm}$ and $1.3 \mathrm{~mm}$, maximum stress intensity factors $K I$ of the fixture at crack tip are $295.899 \mathrm{MPa}$. $\mathrm{mm}^{1 / 2}$ and $382.171 \mathrm{MPa} \cdot \mathrm{mm}^{1 / 2}$, respectively. According to the fracture toughness of $300 \mathrm{MPa} \cdot \mathrm{mm}^{1 / 2}$ of the fixture acquired by Wum et al. [38], the crack length of $1.2 \mathrm{~mm}$ is considered to be finial failure length of this fixture.

It can be seen from this that the corresponding $\mathrm{d} a$ and $\Delta K_{\text {eff }}$ in classical Paris Erdogan Law can obtain the corresponding $\mathrm{d} N$ after determining the coefficient $C$ and $m$ related to the material. Figure 16 indicates the load cycle number versus crack length of the fixture obtained by the boundary element method. It can be found that the crack growth is at a relatively slow rate if the crack length is less than $1.2 \mathrm{~mm}$. Accordingly, the fatigue life of zirconia grinding fixture is approximated to $1.6 \times 10^{4}$ when crack limit length is confirmed to be $1.2 \mathrm{~mm}$. According to the usage experience, the cyclic number of the fixtures is about 100 times per day. To maximize production safety, the number of cycles is supposed to be $1.5 \times 10^{4}$. In other words, the fatigue life can be considered as $15000 / 100=150$ days. Therefore, it is recommended that a monthly inspection of 


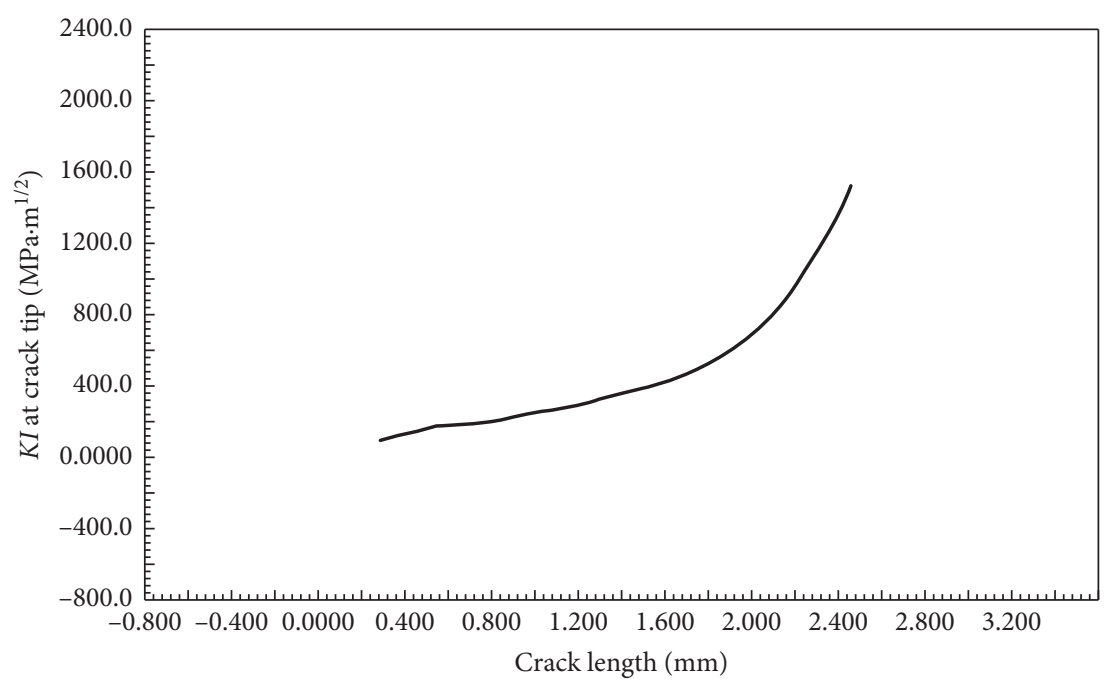

Figure 15: KI values of the fixture at crack tip with respect to crack length.

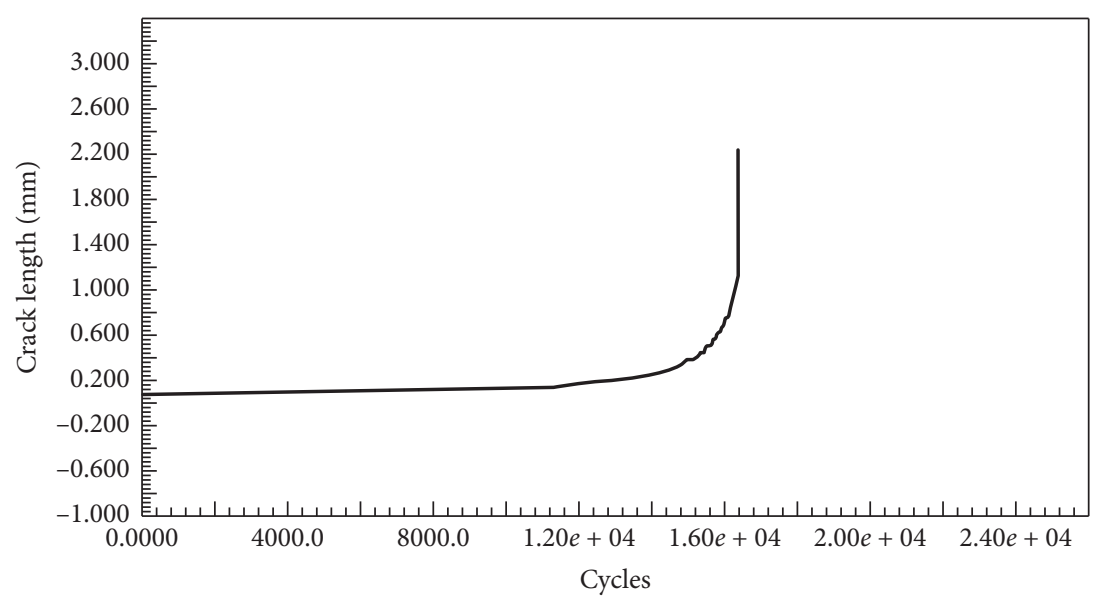

FIGURE 16: Relationships between cycle number and crack length.

the appearance of the fixture should be executed during the production manufacturing process. In addition, once the crack length in the pillar reaches $1.2 \mathrm{~mm}$, the fixture should be replaced to avoid a sudden fracture of the fixture.

\section{Conclusions}

In this study, the BEM was developed to predict fatigue life of the zirconia fixture. To validate the proposed method, the stress intensity factors of plate structures with a unilateral precrack and bilateral precracks are investigated. Compared with the theoretical solutions and the FEM, numerical results by the BEM provide a high accuracy in predicting the SIF. The results show that the crack propagation will sharply increase the SIF at crack tip. On this basis, the crack propagation and service life of the zirconia grinding fixture under cyclic load are further studied. The results indicate that the maximum stress is located at the root of the pillar, and the crack length of $1.2 \mathrm{~mm}$ is suggested to be the finial failure length of the fixture to avoid a sudden fracture for the fixture.

\section{Data Availability}

The raw/processed data required to reproduce these findings cannot be shared at this time due to technical and time limitations.

\section{Conflicts of Interest}

The authors declare no conflicts of interest.

\section{Acknowledgments}

This work was supported by the National Natural Science Foundation of China (no. 51675397), National Natural Science Foundation of Shaanxi Province (no. 2018JZ5005), China Scholarship Council (no. 201706965037), Fundamental Research Funds for the Central Universities (no. XJS190405), and the 111 Project (no. B14042). The first author is grateful to the Engineering Department, Lancaster University, for the support he has received during the course of his visit. 


\section{References}

[1] J. Fan, T. Lin, F. Hu et al., "Effect of sintering temperature on microstructure and mechanical properties of zirconiatoughened alumina machinable dental ceramics," Ceramics International, vol. 43, no. 4, pp. 3647-3653, 2017.

[2] G. Majumdar, M. Chakraborty, and M. S. J. Hashmi, "Fine grinding of semiconductor materials: review of past and current practices," International Journal of Machine Tools \& Manufacture, vol. 48, pp. 1297-1307, 2008.

[3] S. Agarwal and P. Venkateswara Rao, "Modeling and prediction of surface roughness in ceramic grinding," International Journal of Machine Tools and Manufacture, vol. 50, no. 12, pp. 1065-1076, 2010.

[4] H. Chai, J. J.-W. Lee, A. J. Mieleszko, S. J. Chu, and Y. Zhang, "On the interfacial fracture of porcelain/zirconia and graded zirconia dental structures," Acta Biomaterialia, vol. 10, no. 8, pp. 3756-3761, 2014.

[5] M. I. Abdelhamed, J. D. Galley, and M. T. Bailey, "A comparison of zirconia and titanium abutments for microleakage," Clinical Implant Dentistry and Related Research, vol. 17, pp. e643-e651, 2015.

[6] J. Ye, C. Chu, H. Cai et al., "A multi-scale model for studying failure mechanisms of composite wind turbine blades," Composite Structures, vol. 212, pp. 220-229, 2019.

[7] T. C. Eric and S. L. Chak, "A mixed generalized multiscale finite element method for planar linear elasticity," Journal of Computational and Applied Mathematics, vol. 348, pp. 298313, 2019.

[8] H. Almanasreh, "Finite element method for solving the Dirac eigenvalue problem with linear basis functions," Journal of Computational Physics, vol. 376, pp. 1199-1211, 2018.

[9] J. J. Ye, C. C. Chu, H. Cai et al., "A multi-scale modeling scheme for damage analysis of composite structures based on the high-fidelity generalized method of cells," Composite Structures, vol. 206, pp. 42-53, 2018.

[10] A. A. Hedayat, E. A. Afzadi, and A. Iranpour, "Prediction of the bolt fracture in shear using finite element method," Structures, vol. 12, pp. 188-210, 2017.

[11] T. Sano, D. Sasaki, M. Koyama, S. Hamada, and H. Noguchi, "Proposal and verification of novel fatigue crack propagation simulation method by finite element method," Procedia Structural Integrity, vol. 13, pp. 1154-1158, 2018.

[12] J. M. Alegre and I. I. Cuesta, "Some aspects about the crack growth FEM simulations under mixed-mode loading," International Journal of Fatigue, vol. 32, no. 7, pp. 1090-1095, 2010.

[13] Y. Liu, S. Lemanski, X. Zhang, D. Ayre, and H. Y. Nezhad, "A finite element study of fatigue crack propagation in single lap bonded joint with process-induced disbond," International Journal of Adhesion and Adhesives, vol. 87, pp. 164-172, 2018.

[14] Q. Y. Chen and X. M. Chen, "Effect of incision Angle and depth on the strength of zirconia ceramic," Journal of Modern Stomatology, vol. 6, pp. 450-453, 2011.

[15] Q. Chen and X. Chen, "The effect of notch's angle and depth on crack propagation of zirconia ceramics," Journal of Modern Stomatology, vol. 29, pp. 913-918, 2011.

[16] H. M. El-sayed, M. Lotfy, H. N. E. Zohny, and H. S. Riad, "Prediction of fatigue crack initiation life in railheads using finite element analysis," Ain Shams Engineering Journal, vol. 9, pp. 2329-2342, 2017.

[17] J. X. Xue, "Simulation research on metal machining mechanism by finite element method," Machine Building \& Automation, vol. 2, pp. 1-7, 2013.
[18] J. Liu, G. Lin, and J. Du, "Fracture analysis of multiple crack problems based on SBFEM," Journal of Dalian University of Technology, vol. 48, pp. 392-397, 2008.

[19] W. Gao, S. Wang, and X. Yan, "Calculation and analysis of stress intensity factor for inclined semi-elliptical surface crack based on boundary element method," Mechanical Strength, vol. 35, pp. 503-508, 2013.

[20] S. Najafi and M. Abbaspoor, "Numerical investigation of flow pattern and hydrodynamic forces of submerged marine propellers using unsteady boundary element method," Proceedings of the Institution of Mechanical Engineers, Part M: Journal of Engineering for the Maritime Environment, vol. 233, no. 1, pp. 67-79, 2017.

[21] X. Chen, T. Luo, E. T. Ooi, E. H. Ooi, and C. Song, “A quadtree-polygon-based scaled boundary finite element method for crack propagation modeling in functionally graded materials," Theoretical and Applied Fracture Mechanics, vol. 94, pp. 120-133, 2018.

[22] Z. Ming and Z. Yong-yuan, "The analysis of dynamic stress intensity factor for semi-circular surface crack using timedomain BEM formulation," Applied Mathematics and Mechanics, vol. 22, no. 11, pp. 1344-1351, 2001.

[23] R. G. Peixoto, G. O. Ribeiro, and R. L. S. Pitangueira, "A boundary element method formulation for quasi-brittle material fracture analysis using the continuum strong discontinuity approach," Engineering Fracture Mechanics, vol. 202, pp. 47-74, 2018.

[24] H. T. Wang and Z. H. Yao, "Large-scale thermal analysis of fiber composites using a line-inclusion model by the fast boundary element method," Engineering Analysis with Boundary Elements, vol. 37, no. 2, pp. 319-326, 2013.

[25] P.-M. Hilgendorff, A. Grigorescu, M. Zimmermann, C.-P. Fritzen, and H.-J. Christ, "Simulation of irreversible damage accumulation in the very high cycle fatigue (VHCF) regime using the boundary element method," Materials Science and Engineering: A, vol. 575, pp. 169-176, 2013.

[26] H. Cai, J. J. Ye, Y. W. Wang et al., "An effective microscale approach for determining the anisotropy of polymer composites reinforced with randomly distributed short fibers," Composite Structures, vol. 240, Article ID 112087, 2020.

[27] J. Ye, Y. Wang, Z. Li et al., "Failure analysis of fiber-reinforced composites subjected to coupled thermo-mechanical loading," Composite Structures, vol. 235, Article ID 111756, 2020.

[28] J. Ye, Y. Hong, H. Cai, Y. Wang, Z. Zhai, and B. Shi, “A new three-dimensional parametric FVDAM for investigating the effective elastic moduli of particle-reinforced composites with interphase," Mechanics of Advanced Materials and Structures, vol. 26, no. 22, pp. 1870-1880, 2019.

[29] P. Shi, "Singular integral equation method for $2 \mathrm{D}$ fracture analysis of orthotropic solids containing doubly periodic strip-like cracks on rectangular lattice arrays under longitudinal shear loading," Applied Mathematical Modelling, vol. 77, pp. 1460-1473, 2020.

[30] X. Chen, Z. He, B. Li, and J. Xiang, "An efficient wavelet finite element method in fault prognosis of incipient crack," Science in China Series E, vol. 49, no. 1, pp. 89-101, 2006.

[31] J. J. Ye, Y. M. He, X. F. Chen, Z. Zhai, Y. M. Wang, and Z. J. He, "Pipe crack identification based on finite element method of second generation wavelets," Mechanical Systems and Signal Processing, vol. 24, no. 2, pp. 379-393, 2010.

[32] J. Xiang, X. Chen, Q. Mo, and Z. He, "Identification of crack in a rotor system based on wavelet finite element method," Finite Elements in Analysis and Design, vol. 43, no. 14, pp. 10681081, 2007. 
[33] T. A. Cruse, Boundary Element Analysis in Computational Fracture Mechanics, pp. 41-65, Kluwer Academic Publishers, Dordrecht, Netherlands, 1988.

[34] F. Erdogan and G. C. Sih, "On the crack extension in plates under plane loading and transverse shear," Journal of Basic Engineering, vol. 85, no. 4, pp. 519-525, 1963.

[35] Y. Murakmi, Stress Intensity Factors Handbook, vol. 1, pp. 239-240, Pergamon Press World Publishing Corporation, Evanston, IL, USA, 1982.

[36] P. Paris and F. Erdogan, "A critical analysis of crack propagation laws," Journal of Basic Engineering, vol. 85, no. 4, pp. 528-533, 1963.

[37] K. Vladimir, "Unification proposals for fatigsue crack propagation laws," Multidiscipline Modeling in Materials and Structures, vol. 13, pp. 262-283, 2017.

[38] Y. Wum, Y. C. Shen, and S. H. Li, "Simulation and experimental study on surface quality of zirconia ceramic grinding," Machinery \& Electronics, vol. 3, pp. 1-9, 2017. 